Proc. Estonian Acad. Sci. Eng., 2004, 10, 4, 281-289

\title{
Linear stability analysis of shear-flexible thin-walled beams
}

\author{
Domagoj Lanc, Goran Turkalj and Josip Brnić \\ Faculty of Engineering, University of Rijeka, Vukovarska 58, 51000 Rijeka, Croatia; \{dlanc, \\ turkalj,brnic\}@ riteh.hr \\ Received 1 July 2004, in revised form 17 September 2004

\begin{abstract}
This paper presents finite element based numerical stability analysis of thin-walled beam structures. Using the linearized virtual work principle with the assumption of large displacements, large rotations but small strains, a finite element equation is derived. Effects of cross-sectional shear deformations are also taken into account. To include large rotation effects, non-linear displacement field of the cross-section is used. A new two-node shear-flexible finite element with seven degrees of freedom per node is developed. Complete exact $14 \times 14$ elastic and geometric stiffness matrices are evaluated. An original computer program THINWALL-SHEAR is developed. Obtained results are compared with analytical and numerical results of other authors.
\end{abstract}

Key words: thin-walled beam, large displacements, large rotations, shear deformations.

\section{INTRODUCTION}

Tendency to optimize constructions and to reduce the production costs appeals for using thin-walled structures because they offer a high performance for a minimum weight. Complexity of their behaviour, especially from the point of view of the loss of stability, imposes numerical modelling because theoretical solutions are limited with cases of simple geometry.

Linear analysis treats stability as an eigenvalue problem and determines the critical load in a direct manner without calculating the deformations. The critical buckling load corresponds to the lowest eigenvalue and the corresponding eigenvector represents the buckling mode. Such an analysis supposes an ideal structure and loading conditions, ignoring deformations before reaching the buckling load. Buckling load is considered to determine the load-carrying capacity.

Stability analysis, concerning large spatial rotation, is very complicated because of the non-vectorial nature of large rotations. Using standard linear 
displacement field, torsional moment is of semitangential and bending moments are of quasitangential character; thus they induce non-compatible moments during large spatial rotations. In this work, non-linear displacement field is used which include large rotation effects. The derived geometric stiffness matrix of the finite element of the thin-walled beam includes all internal moments of semitangential character.

This work also assumes that the beam member is prismatic and straight, material is isotropic, cross-section is non-deformable in his own plane but it can warp, external loads are conservative and constitutive equations are linear.

\section{BASIC CONSIDERATIONS}

\subsection{Non-linear displacement field}

Cross-section displacements consist of seven components: three translational components $w_{o}, u_{s}, v_{s}$, three rotational components $\varphi_{x}, \varphi_{y}, \varphi_{z}$ and cross-sectional warping $\theta$. In the right-handed Cartesian coordinate system $(z, x, y)$, axis $z$ coincides with the beam axis passing through the centroids $\mathrm{O}$ of the crosssections. Coordinate axes $x$ and $y$ are the principal axes of inertia of the crosssection (Fig. 1).

Total displacement field is

$$
\mathbf{U}_{u k}^{\mathrm{T}}=\left\{\begin{array}{lll}
w+\tilde{w} & u+\tilde{u} & v+\tilde{v}
\end{array}\right\},
$$

where $w, u$ and $v$ are linear displacement field components:

$$
w=w_{o}-y \varphi_{x}-x \varphi_{y}-\omega \theta, \quad u=u_{s}-\left(y-y_{s}\right) \varphi_{z}, \quad v=v_{s}+\left(x-x_{s}\right) \varphi_{z},
$$

and $\tilde{w}, \tilde{u}$ and $\tilde{v}$, are second-order components:

$$
\begin{aligned}
& \tilde{w}=\frac{1}{2}\left[\varphi_{z} \varphi_{x}\left(x-x_{s}\right)+\varphi_{z} \varphi_{y}\left(y-y_{s}\right)\right], \\
& \tilde{u}=\frac{1}{2}\left[\varphi_{z}^{2} x_{s}+\varphi_{x} \varphi_{y} y-\left(\varphi_{z}^{2}+\varphi_{y}^{2}\right) x\right], \\
& \tilde{v}=\frac{1}{2}\left[\varphi_{z}^{2} y_{s}+\varphi_{x} \varphi_{y} x-\left(\varphi_{z}^{2}+\varphi_{x}^{2}\right) y\right] .
\end{aligned}
$$

Using non-linear displacement field, the corresponding Green-Lagrange strain tensor is

$$
\varepsilon_{i j} \cong e_{i j}+\eta_{i j}+\tilde{e}_{i j}
$$

with components defined as $\left[{ }^{1}\right]$ :

$$
e_{i j}=\frac{1}{2}\left(u_{i, j}+u_{j, i}\right), \quad \eta_{i j}=\frac{1}{2}\left(u_{k, i} u_{k, j}\right), \quad \tilde{e}_{i j}=\frac{1}{2}\left(\tilde{u}_{i, j}+\tilde{u}_{j, i}\right) .
$$



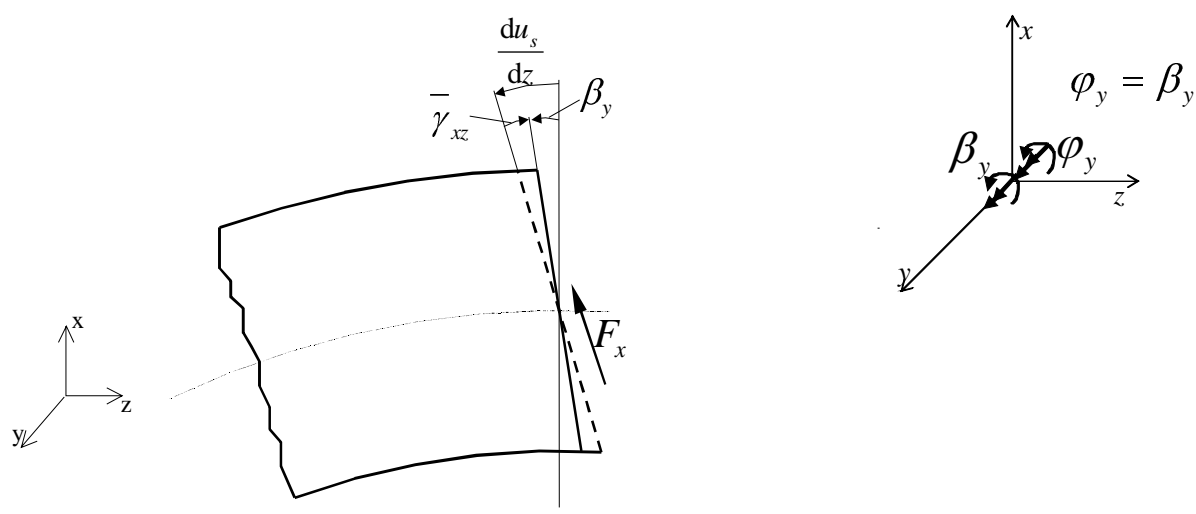

Fig. 1. Shear deformation in $\mathrm{x}-\mathrm{z}$ plane.

Cross-sectional stress resultants generally consist of the axial force $F_{z}=$ $\int_{A} \sigma_{z} \mathrm{~d} A$, shear forces $F_{x}=\int_{A} \tau_{z x} \mathrm{~d} A$ and $F_{y}=\int_{A} \tau_{z y} \mathrm{~d} A$, torsional moment $\stackrel{M}{A}_{z}=\int_{A}\left[\tau_{z y}\left(x-x_{s}\right)-\tau_{z x}\left(y-y_{s}\right)\right] \mathrm{d} A$, bending moments $M_{x}=\int_{A} \sigma_{z} y \mathrm{~d} A$ and $M_{y}=-\int_{A} \sigma_{z} x \mathrm{~d} A$ and bimoment $M_{\omega}=\int_{A} \sigma_{z} \omega \mathrm{d} A$. The torsional moment is the sum of St.Venant's or uniform torsional moment $T_{S V}$ and warping (or nonuniform) torsional moment $T_{\omega}$. Due to restricted cross-sectional warping, an additional component, known as Wagner coefficient $\left[^{2}\right]$, appears. It can be expressed as

$$
\bar{K}=\int_{A} \sigma_{z}\left[\left(x-x_{s}\right)^{2}+\left(y-y_{s}\right)^{2}\right] \mathrm{d} A \quad \text { or } \quad \bar{K}=\alpha_{z} F_{z}+\alpha_{x} M_{x}+\alpha_{y} M_{y}+\alpha_{\omega} M_{\omega} .
$$

Detailed expressions of the coefficients $\alpha_{z}, \alpha_{x}, \alpha_{y}$ and $\alpha_{\omega}$ can be found in $\left[{ }^{3}\right]$. When shear deformations due to $F_{x}, F_{y}$ and $T_{\omega}$ are taken into account, we have

$$
\frac{\mathrm{d} v_{s}}{\mathrm{~d} z}+\varphi_{x}=\bar{\gamma}_{z y}, \quad \frac{\mathrm{d} u_{s}}{\mathrm{~d} z}-\varphi_{y}=\bar{\gamma}_{z x}, \quad \frac{\mathrm{d} \varphi_{s}}{\mathrm{~d} z}+\theta=\bar{\gamma}_{\omega} .
$$

In the plane $x-z$, according to Fig. 1 , we have

$$
\begin{gathered}
\frac{\mathrm{d} u_{s}}{\mathrm{~d} z}-\beta_{y}=\frac{\mathrm{d} u_{s}}{\mathrm{~d} z}-\varphi_{y}=\bar{\gamma}_{x z}, \quad M_{y}=E I_{y} \frac{\mathrm{d} \varphi_{y}}{\mathrm{~d} z}, \\
F_{x}=\bar{\tau}_{z x} A_{x}=G \bar{\gamma}_{x z} A_{x}=\frac{G A}{k_{x}}\left(\frac{\mathrm{d} u_{s}}{\mathrm{~d} z}-\varphi_{y}\right),
\end{gathered}
$$

and analogously for bending in $z-y$ plane follows:

$$
\begin{gathered}
\frac{\mathrm{d} v_{s}}{\mathrm{~d} z}-\beta_{x}=\frac{\mathrm{d} v_{s}}{\mathrm{~d} z}+\varphi_{x}=\bar{\gamma}_{z y}, \quad M_{x}=E I_{x} \frac{\mathrm{d} \varphi_{x}}{\mathrm{~d} z}, \\
F_{y}=\bar{\tau}_{z y} A_{y}=G \bar{\gamma}_{z y} A_{y}=\frac{G A}{k_{y}}\left(\varphi_{x}+\frac{\mathrm{d} v_{s}}{\mathrm{~d} z}\right),
\end{gathered}
$$


and for torsion:

$$
\frac{\mathrm{d} \varphi_{z}}{\mathrm{~d} z}+\theta=\bar{\gamma}_{\omega}, \quad M_{\omega}=E I_{\omega} \frac{\mathrm{d} \theta}{\mathrm{d} z} ; \quad T_{S V}=G J \frac{\mathrm{d} \varphi_{z}}{\mathrm{~d} z}, \quad T_{\omega}=G \bar{\gamma}_{\omega} J_{\omega}=\frac{G J}{k_{\omega}}\left(\frac{\mathrm{d} \varphi_{z}}{\mathrm{~d} z}+\theta\right) .
$$

In relations above, $\bar{\gamma}_{x z}, \bar{\gamma}_{z y}$ and $\bar{\gamma}_{\omega}$ are average values of shear deformations, $\bar{\tau}_{x z}$ and $\bar{\tau}_{z y}$ are average values of shear stresses, $A_{x}, A_{y}$ and $J_{\omega}$ are shear areas with respect to $x, y$ and $\omega$, and $k_{x}, k_{y}$ and $k_{\omega}$ are flexible shear coefficients.

Flexible shear coefficients can be evaluated as

$$
k_{x}=\frac{A}{I_{y}^{2}} \int_{S} C_{y}^{2} \frac{\mathrm{d} S}{t}, \quad k_{y}=\frac{A}{I_{x}^{2}} \int_{S} C_{x}^{2} \frac{\mathrm{d} S}{t}, \quad k_{\omega}=\frac{A}{I_{\omega}^{2}} \int_{S} C_{\omega}^{2} \frac{\mathrm{d} S}{t},
$$

where $C_{x}, C_{y}$ and $C_{\omega}$ are first moments of the cross-section with respect to $x, y$ and $\omega$, defined as

$$
C_{y}=\int_{A} x \mathrm{~d} A=\int_{0}^{S} x t \mathrm{~d} S, \quad C_{x}=\int_{A} y \mathrm{~d} A=\int_{0}^{S} y t \mathrm{~d} S, \quad C_{\omega}=\int_{A} \omega \mathrm{d} A=\int_{0}^{S} \omega t \mathrm{~d} S .
$$

\subsection{The principle of virtual work}

From the equilibrium between internal and external forces follows $\left[{ }^{4,5}\right]$ :

$$
\int_{\mathrm{V}} S_{i j} \delta e_{i j} \mathrm{~d} V+\int_{V}^{0} S_{i j} \delta \eta_{i j} \mathrm{~d} V+\int_{V}^{0} S_{i j} \delta \tilde{e}_{i j} \mathrm{~d} V-\int_{A_{\sigma}}^{0} t_{i} \delta \tilde{u}_{i} \mathrm{~d} A_{\sigma}=\int_{A_{\sigma}} t_{i} \delta u_{i} \mathrm{~d} A_{\sigma} .
$$

Equation (14) is known as linearized principle of virtual work and it can be rewritten as $\left[^{6}\right]$ :

$$
\delta \mathrm{U}_{E}+\delta \mathrm{U}_{G}-\delta W=\delta \Pi=0,
$$

where $\delta \mathrm{U}_{E}$ is the elastic potential energy of internal forces, $\delta \mathrm{U}_{G}$ is the geometric potential of initial forces, $\delta \mathrm{W}$ is the virtual work of external forces and $\Pi$ is total potential energy:

$$
\begin{gathered}
\delta \mathrm{U}_{E}=\int_{V} S_{i j} \delta e_{i j} \mathrm{~d} V, \\
\delta \mathrm{U}_{G}=\int_{S_{i j}}^{0} S_{i j} \delta \eta_{i j} \mathrm{~d} V+\int_{V}^{0} S_{i j} \delta \tilde{e}_{i j} \mathrm{~d} V-\int_{A_{\sigma}}^{0} t_{i} \delta \tilde{u}_{i} \mathrm{~d} A_{\sigma}, \\
\delta W=\int_{A_{\sigma}} t_{i} \delta u_{i} \mathrm{~d} A_{\sigma} .
\end{gathered}
$$


Introducing (1)-(6) into equations for $\delta \mathrm{U}_{E}$ and $\delta \mathrm{U}_{G}$ gives

$$
\begin{aligned}
\delta \mathrm{U}_{E}=\int_{0}^{1}\left[E A \frac{\mathrm{d} w_{o}}{\mathrm{~d} z} \delta \frac{\mathrm{d} w_{o}}{\mathrm{~d} z}\right. & +E I_{x} \frac{\mathrm{d} \varphi_{x}}{\mathrm{~d} z} \delta \frac{\mathrm{d} \varphi_{x}}{\mathrm{~d} z}+E I_{y} \frac{\mathrm{d} \varphi_{y}}{\mathrm{~d} z} \delta \frac{\mathrm{d} \varphi_{y}}{\mathrm{~d} z}+E I_{\omega} \frac{\mathrm{d} \theta}{\mathrm{d} z} \delta \frac{\mathrm{d} \theta}{\mathrm{d} z} \\
& +G J \frac{\mathrm{d} \varphi_{z}}{\mathrm{~d} z} \delta \frac{\mathrm{d} \varphi_{z}}{\mathrm{~d} z}+\frac{G A}{k_{y}}\left(\frac{\mathrm{d} v_{s}}{\mathrm{~d} z}-\varphi_{x}\right)^{2}+\frac{G A}{k_{x}}\left(\frac{\mathrm{d} u_{s}}{\mathrm{~d} z}+\varphi_{y}\right)^{2} \\
& \left.+\frac{G J}{k_{\omega}}\left(\frac{\mathrm{d} \varphi_{z}}{\mathrm{~d} z}+\theta\right)^{2}\right] \mathrm{d} z
\end{aligned}
$$

$$
\begin{aligned}
& \delta \mathrm{U}_{G}= \\
& \frac{1}{2} \int_{0}^{l} \int_{0}^{0} F_{z}\left[\delta\left(\frac{\mathrm{d} w_{o}}{\mathrm{~d} z}\right)^{2}+\delta\left(\frac{\mathrm{d} v_{s}}{\mathrm{~d} z}\right)^{2}+\delta\left(\frac{\mathrm{d} u_{s}}{\mathrm{~d} z}\right)^{2}+2 y_{s} \delta\left(\frac{\mathrm{d} u_{s}}{\mathrm{~d} z} \frac{\mathrm{d} \varphi_{z}}{\mathrm{~d} z}\right)-2 x_{s \delta}\left(\frac{\mathrm{d} v_{s}}{\mathrm{~d} z} \frac{\mathrm{d} \varphi_{z}}{\mathrm{~d} z}\right)\right] \\
& +{ }^{0} F_{x}\left[\delta\left(\varphi_{x} \varphi_{z}\right)+2 \delta\left(\frac{\mathrm{d} v_{s}}{\mathrm{~d} z} \varphi_{z}\right)-2 \delta\left(\frac{\mathrm{d} w_{o}}{\mathrm{~d} z} \varphi_{y}\right)+2 x_{s} \delta\left(\frac{\mathrm{d} \varphi_{y}}{\mathrm{~d} z} \varphi_{y}\right)-2 y_{s} \delta\left(\frac{\mathrm{d} \varphi_{x}}{\mathrm{~d} z} \varphi_{y}\right)\right] \\
& +{ }^{0} F_{y}\left[\delta\left(\varphi_{y} \varphi_{z}\right)-2 \delta\left(\frac{\mathrm{d} u_{s}}{\mathrm{~d} z} \varphi_{z}\right)+2 \delta\left(\frac{\mathrm{d} w_{o}}{\mathrm{~d} z} \varphi_{x}\right)-2 x_{s} \delta\left(\frac{\mathrm{d} \varphi_{y}}{\mathrm{~d} z} \varphi_{x}\right)-2 y_{s} \delta\left(\frac{\mathrm{d} \varphi_{x}}{\mathrm{~d} z} \varphi_{x}\right)\right] \\
& +{ }^{0} M_{x}\left[\delta\left(\frac{\mathrm{d} \varphi_{y}}{\mathrm{~d} z} \varphi_{z}\right)+\delta\left(\frac{\mathrm{d} \varphi_{z}}{\mathrm{~d} z} \varphi_{y}\right)-2 \delta\left(\frac{\mathrm{d} u_{s}}{\mathrm{~d} z} \frac{\mathrm{d} \varphi_{z}}{\mathrm{~d} z}\right)+2 \delta\left(\frac{\mathrm{d} w_{o}}{\mathrm{~d} z} \frac{\mathrm{d} \varphi_{x}}{\mathrm{~d} z}\right)\right] \\
& +{ }^{0} M_{y}\left[-\delta\left(\frac{\mathrm{d} \varphi_{x}}{\mathrm{~d} z} \varphi_{z}\right)-\delta\left(\frac{\mathrm{d} \varphi_{z}}{\mathrm{~d} z} \varphi_{x}\right)-2 \delta\left(\frac{\mathrm{d} v_{s}}{\mathrm{~d} z} \frac{\mathrm{d} \varphi_{z}}{\mathrm{~d} z}\right)+2 \delta\left(\frac{\mathrm{d} w_{o}}{\mathrm{~d} z} \frac{\mathrm{d} \varphi_{y}}{\mathrm{~d} z}\right)\right] \\
& \left.+{ }^{0} M_{z}\left[\delta\left(\frac{\mathrm{d} \varphi_{x}}{\mathrm{~d} z} \varphi_{y}\right)-\delta\left(\frac{\mathrm{d} \varphi_{y}}{\mathrm{~d} z} \varphi_{x}\right)\right]+{ }^{0} \bar{K} \delta\left(\frac{\mathrm{d} \varphi_{z}}{\mathrm{~d} z}\right)^{2}+{ }^{0} M_{\omega}\left[\delta\left(\frac{\mathrm{d} w_{o}}{\mathrm{~d} z} \frac{\mathrm{d} \theta}{\mathrm{d} z}\right)\right]\right\} \mathrm{d} z .
\end{aligned}
$$

\section{FINITE ELEMENT OF THE THIN-WALLED BEAM}

In Fig. 2 the finite element of the thin-walled beam with 14 degrees of freedom is shown $\left[{ }^{7,8}\right]$. The nodal displacement vector $\mathbf{u}^{e}$ and force vector $\mathbf{f}^{e}$ of an arbitrary $e$ th element are:

$$
\left(\mathbf{u}^{e}\right)^{T}=\left\{w_{o i} u_{s i} v_{s i} \varphi_{z i} \varphi_{x i} \varphi_{y i} \theta_{i}\right\}, \quad\left(\mathbf{f}^{e}\right)^{T}=\left\{F_{z i} F_{x i} F_{y i} M_{z i} M_{x i} M_{y i} M_{\omega i}\right\} .
$$

For the finite element the equilibrium equation holds

$$
\left(\mathbf{k}_{E}^{e}+\mathbf{k}_{G}^{e}\right) \mathbf{u}^{e}=\mathbf{f}^{e},
$$




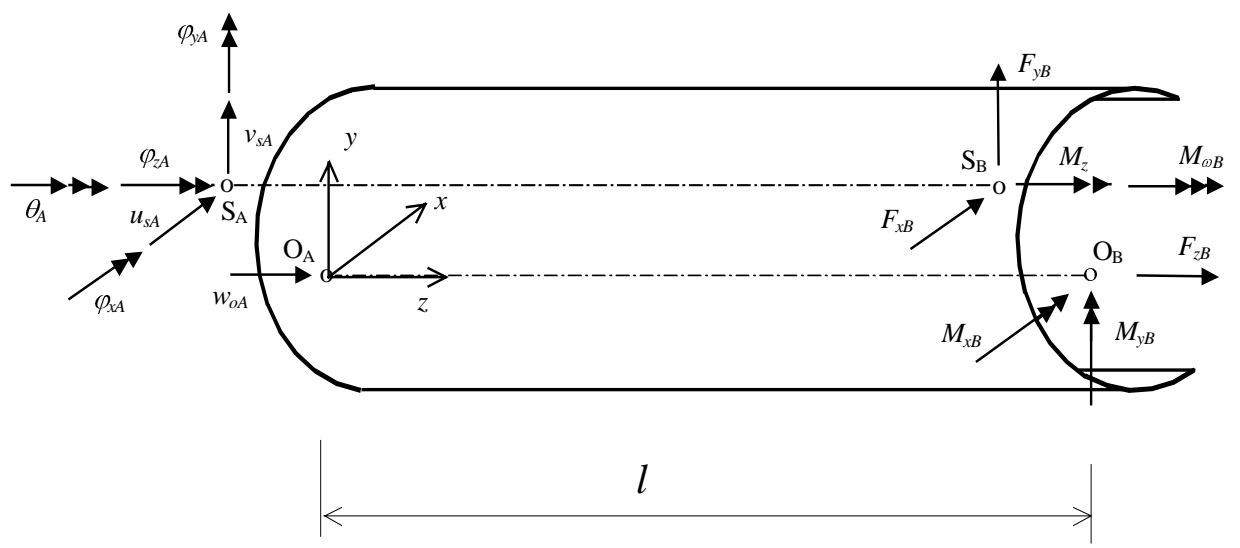

Fig. 2. Finite element of the thin-walled beam.

where $\mathbf{k}_{E}^{e}$ and $\mathbf{k}_{G}^{e}$ are elastic and geometric parts of the stiffness matrix in local coordinate system, which are obtained by solving integrals for $\delta \mathrm{U}_{E}$ and $\delta \mathrm{U}_{G}$ $\left[{ }^{9}\right]$. Interpolation functions for displacement components $\mathbf{w}$ are linear and for $\mathbf{u}, \mathbf{v}$ and $\boldsymbol{\varphi}$ cubic interpolation is used. For the whole construction, equilibrium equation (assuming proportionality of loading) is

$$
\left(\mathbf{K}_{E}+\lambda \hat{\mathbf{K}}_{G}\right) \mathbf{U}=\mathbf{F},
$$

where $\mathbf{K}_{E}$ is the elastic stiffness matrix of the construction, $\mathbf{K}_{G}$ is geometric stiffness matrix of the construction, $\mathbf{U}$ and $\mathbf{F}$ are vectors of incremental nodal displacements and nodal forces and $\lambda$ is load parameter. Assuming that the external load does not change during the losing of stability $(\mathbf{F}=0)$, Eq. (19) becomes

$$
\left(\mathbf{K}_{E}+\lambda \hat{\mathbf{K}}_{G}\right) \mathbf{U}=0
$$

Solving Eq. (20) for eigenvalues is called linear stability analysis $\left[{ }^{1}\right]$ and eigenvalues $\lambda_{1}, \ldots, \lambda_{n}$ represent critical buckling loads. Only the first value $\lambda_{1}$ is of practical interest $\left[{ }^{10}\right]$.

\section{EXAMPLE}

Computer program THINWALL-SHEAR, developed on the basis of the presented theory, is tested on a two examples.

\subsection{Torsional-flexural buckling of a cantilever}

A cantilever of unsymmetrical cross-section, loaded with axial force at the centroid, is shown in Fig. 3. 


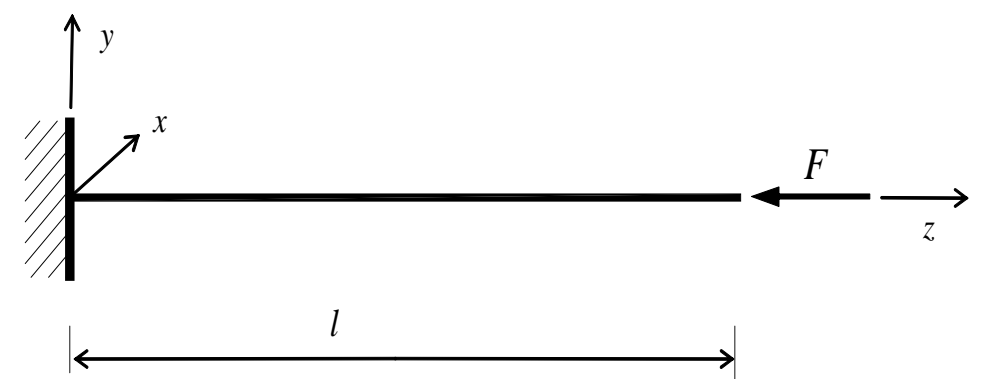

Fig. 3. Axially compressed cantilever of unsymmetrical cross-section (example 4.1).

Table 1. Values of $F_{\mathrm{cr}}(\mathrm{N})$ for the cantilever (example 4.1)

\begin{tabular}{c|c|c|c}
\hline Number of elements & This paper & Kim et. al. $\left[{ }^{3}\right]$ & ABAQUS $\left[{ }^{11}\right]$ \\
\hline 1 & 13.9958 & & \\
2 & 13.8986 & 13.9017 & 14.0230 \\
4 & 13.8930 & &
\end{tabular}

Material and geometrical parameters are the following: $l=200 \mathrm{~cm}, E=$ $30000 \mathrm{Ncm}^{-2}, G=11500 \mathrm{Ncm}^{-2}$; shear centre coordinates: $x_{s}=1.58943 \mathrm{~cm}$, $y_{s}=-2.57228 \mathrm{~cm}$; moments of inertia: $I_{x}=114.812 \mathrm{~cm}^{4}, I_{y}=7.6048 \mathrm{~cm}^{4}$; warping moment of inertia $I_{\omega}=70.9687 \mathrm{~cm}^{6}$; torsional moment of inertia $J=$ $0.666667 \mathrm{~cm}^{4}$; shear factors: $k_{x}=5.2339, k_{y}=1.794438, k_{\omega}=0.01699$; Wagner coefficients: $\alpha_{x}=5.66166 \mathrm{~cm}, \alpha_{y}=11.0599 \mathrm{~cm}, \alpha_{z}=24.445 \mathrm{~cm}^{2}, \alpha_{\omega}=-0.558603$. Values for critical buckling load $F_{\text {cr }}$, evaluated by program THINWALL-SHEAR are compared with the finite element results from $\left[{ }^{3}\right]$, and with the results obtained with ABAQUS $\left[{ }^{11}\right]$ (where an idealized cantilever with 1600 shell finite elements was used. Table 1 shows very good accuracy of the results obtained with ABAQUS.

\subsection{Flexural buckling of a simply supported beam}

The simply supported beam in Fig. 4 has doubly symmetric cross-section. The beam is axially loaded with compression force $F$. Due to double symmetry of the cross-section, the only possible buckling mode is flexural.

The relevant material and geometrical properties of the beam are: $l=100 \mathrm{~cm}$, $E=2.1 \times 10^{7} \mathrm{Ncm}^{-2}, G=80.77 \times 10^{5} \mathrm{Ncm}^{-2}$; moments of inertia: $I_{x}=I_{y}=$ $50 \mathrm{~cm}^{4}$; cross-section area $A=5 \mathrm{~cm}^{2}$. In Table 2 , results obtained with program THINWALL-SHEAR are compared with numerical results and Timoshenko's analytical results, given in $\left[{ }^{3}\right]$ for different values of the shear coefficient $k=$ $k_{x}=k_{y}$. Table 2 shows very good coincidence of the results. 


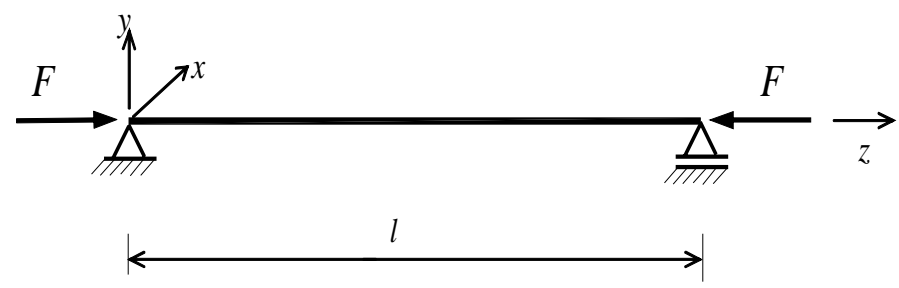

Fig. 4. Axially compressed simply supported beam of doubly symmetrical cross-section (example 4.2).

Table 2. Values of $F_{\text {cr }}\left(\times 10^{-6} \mathrm{~N}\right)$ for flexural buckling of the beam under axial load

\begin{tabular}{c|c|c|c|c}
\hline \multirow{2}{*}{$\frac{k}{G A} F_{\text {cr }}$} & \multicolumn{2}{|c|}{ THINWALL-SHEAR } & \multirow{2}{*}{$\begin{array}{c}\text { Analytical } \\
\text { (Timoshenko) }\end{array}$} & \multirow{2}{*}{ Kim et al. $\left[^{3}\right]$} \\
\cline { 2 - 3 } & \multicolumn{2}{|c|}{ Number of elements } & & \\
\cline { 2 - 3 } 0 & 2 & 4 & 1.03630 & 1.03641 \\
0.5 & 1.04410 & 1.03684 & 0.69087 & 0.69440 \\
1 & 0.71541 & 0.69059 & 0.51815 & 0.52112 \\
5 & 0.53516 & 0.51548 & 0.17272 & 0.17326 \\
10 & 0.17193 & 0.16879 & 0.09421 & 0.09439 \\
100 & 0.09254 & 0.09156 & 0.01026 & 0.01026 \\
10000 & 0.00992 & 0.00999 & 0.00010 & 0.00010
\end{tabular}

\section{CONCLUSIONS}

Numerical models are efficient alternatives for analytical modelling, which is applicable only in the case of very simple geometry of the structure. Presented numerical algorithm, based on the finite element method, includes large displacements and large rotations and also cross-sectional deformation effects. Coincidence of the results, obtained with the program THINWALL-SHEAR for two typical examples, with the results of other authors available from literature, encourages application of numerical models to problems of more complex constructions.

\section{REFERENCES}

1. Yang, Y. B. and Kuo, S. R. Theory and Analysis of Nonlinear Framed Structures. Prentice Hall, New York, 1994

2. Kim, M. Y., Chang, S. P. and Kim, S. B. Spatial postbuckling analysis of thin-walled frames II: geometrically nonlinear FE procedures. J. Eng. Mech., 2001, 127, 779-790.

3. Kim, M. Y., Chang, S. P. and Kim, S. B. Spatial stability and free vibration of shear flexible thin-walled elastic beams II: numerical approach. Int. J. Numer. Meth. Eng., 1994, 37, 4117-4140.

4. Turkalj, G., Brnic, J. and Prpic-Orsic, J. Large rotation analysis of elastic thin-walled beam-type structures using ESA approach, Comput. Struct., 2003, 81, 1851-1864. 
5. Turkalj, G., Brnic, J. and Prpic-Orsic, J. External stiffness approach for thin-walled frames with elastic-plasticity. In Proc. Sixth International Conference on Computational Structures Technology. (Topping, B. H. V. and Bittnar, Z., eds.), Prague, 2000. Civil-Comp Press, Stirling, 2002, 67-68.

6. Chang, S. P., Kim, S. B. and Kim, M. Y. Stability of shear deformable thin-walled space frames and circular arches. J. Eng. Mech., 1996, 122, 844-854.

7. Bathe, K. J. Finite Element Procedure. Prentice Hall, London, 1996.

8. Mihanovic, A. Stabilnost Konstrukcija. Hrvatsko drustvo gradevinskih konstruktora, Zagreb, 1993 (in Croatian).

9. Turkalj, G. and Brnic, J. Analiza elastičnog izvijanja tankostijenih grednih konstrukcija s obzirom na velike rotacije. Strojarstvo, 2000, 42, 217-230 (in Croatian).

10. Turkalj, G., Brnic, J. and Lanc, D. Elastic-plastic large displacement analysis of thin-walled beam type structures. In System-based Vision for Strategic and Creative Design (Bontempi, F., ed.). Balkema, Lisse, 2003, 639-644.

11. Turkalj, G., Brnic, J. and Lanc, D. Non-linear formulation for elastic stability analysis of thinwalled beam-type structures. In Metal Structures: Design, Fabrication, Economy, (Jarmai, K. and Farkas, J., eds.). Millpress, Rotterdam, 2003, 79-86.

\title{
Õhukeseseinaliste talade nihkedeformeerumise lineaarne stabiilsusanalüüs
}

\author{
Domagoj Lanc, Goran Turkalj ja Josip Brnić
}

Töös käsitletakse analüütiliselt ja lõplike elementide meetodil õhukeseseinaliste talade stabiilsust nihkedeformeerumisel. Viimase arvutamiseks on välja töötatud programm. 